\title{
Molecular Imaging in the Diagnosis of Infectious Endocarditis - the Role of PET and SPECT
}

\author{
Domenico Albano, ${ }^{\circledR}$ Francesco Bertagna, ${ }^{\circledR}$ Raffaele Giubbini ${ }^{\circledR}$ \\ ASST Spedali Civili di Brescia, Brescia, Lombardia - Italy
}

\section{Abstract}

18-fluorine-fluorodeoxyglucose positron emission computed tomography (18F-FDG PET/CT) and singlephoton emission computed tomography (SPECT) using radiolabeled white blood cells (WBC) are non-invasive techniques widely used in the diagnosis of infections, like endocarditis. The aim of our paper was to provide a systematic review of the published data on the use of 18F-FDG PET/CT and SPECT in infective endocarditis (IE). A comprehensive literature search of the PubMed/ MEDLINE, Scopus, Embase and Cochrane library databases was conducted to find relevant published articles about the diagnostic performance of SPECT using WBC and 18F-FDG PET/CT in the diagnosis of infectious endocarditis. Twenty papers were included, with a total of 1,154 patients (166 studies with WBC SPECT and 988 with 18F-FDG PET/CT). From the analyses of the studies, the following results were obtained: both SPECT and PET/CT had good diagnostic accuracy in the study of endocarditis. 18F-FDG PET/CT had good specificity (85.8\%) and lower sensitivity (68\%), with high heterogeneity among the studies; WBC SPECT/ CT had an overall sensitivity of $80 \%$ and specificity of $98 \%$. Specific preparations for PET/CT can affect the diagnostic accuracy of the test. Both 18F-FDG PET/CT and WBC SPECT are useful for the diagnosis of IE, and WBC SPECT appears to be slightly more specific than 18F-FDG PET/CT. A specific diet could influence the diagnostic performance of PET/CT.

\section{Keywords}

Endocarditis,Infectious/ diagnostic imaging; Positron Emission Tomography Computed/methods; Positron Emission Tomography Computed Tomography/ methods; Radiommunodetect/ methods; Leukocytes.

\section{Introduction}

Infectious endocarditis (IE) is a serious, potentially life-threatening condition, and a challenge for clinicians due to difficulties in its diagnosis. ${ }^{1,2}$ The current diagnostic approach often revolves around the modified Duke criteria, which are composed of a composite of clinical criteria, blood cultures and echocardiographic findings, ${ }^{3}$ but cases of uncertain diagnosis are still significant.

Cardiac infections include a group of conditions involving the heart muscle, the pericardium or the endocardial surface of the heart. Infections can extend to the prosthetic material or the leads in case of device implantation. The heterogeneity of clinical presentations requires, besides the diagnostic criteria, a discussion by a multidisciplinary team.

IE is a representative example where the use of nuclear medicine has evolved as an important diagnostic tool. ${ }^{4,5}$

Single photon emission computed tomography (SPECT) using radiolabelled white blood cell (WBC) and fluorine-18-fluorodeoxyglucose positron emission tomography/computed tomography (18F-FDG PET/CT) have been widely used in the diagnosis of infections and in IE, with controversial findings.

The aim of this review is to provide a systematic review of published data about the role of WBC SPECT and 18F-FDG PET/CT in the diagnostic work-up of patients with IE.

\section{Materials and Methods}

The present meta-analysis followed the Preferred Reporting Items for Systematic Reviews and Metaanalyses (PRISMA) statement (see supplementary material for PRISMA Checklist). ${ }^{6}$ 


\section{Search strategy}

A comprehensive literature search of the PubMed/ MEDLINE, Scopus, Embase and Cochrane library databases was conducted to find relevant published articles about the diagnostic accuracy of WBC SPECT and 18F-FDG PET/CT in patients affected by IE. We used a search algorithm based on a combination of the terms: a) "SPECT" OR "Single-photon emission computed tomography" OR "WBC" OR "radiolabeled leukocytes" OR "PET" OR "positron emission tomography" AND b) "endocarditis" OR "heart infection". No beginning date limit was used; the search was updated until August 31, 2019. Only articles in the English language were selected; pre-clinical or not in vivo studies, review, letters, editorials and conference proceedings were excluded. To expand our search, references of the retrieved articles were also screened for additional studies. Studies considering cardiovascular implantable electronic device infections were excluded by this review. All literature studies collected were managed using EndNote Web 3.3.

\section{Study selection}

All articles reporting patients with IE evaluated by WBC SPECT and 18F-FDG PET/CT in clinical setting were eligible for inclusion. Two researchers (DA and FB) independently reviewed the titles and abstracts of the retrieved articles. The same two researchers then independently reviewed the full-text version of the remaining articles to determine their eligibility for inclusion. Disagreements were resolved by a third opinion (RG). Moreover, in case of studies that included the same population, the report with the highest number of enrolled patients was considered for the analysis.

\section{Data abstraction}

For each included study, the following data were extracted - authors' names, year of publication, type of study, number of patients, diagnostic test, diagnostic criteria, reference standard, diagnostic performance. The main findings of the articles included in the review are reported in the Results section.

\section{Results}

\section{Literature search}

The comprehensive computer literature search revealed 665 articles (Figure 1). On reviewing the titles and abstracts, 645 articles were excluded because the data reported data were not within the field of interest of this review. Twenty articles were selected and retrieved in full-text version ${ }^{7-25}$; no additional study was found when screening the references of these articles. In total, 20 articles were included in the systematic review, four about WBC SPECT ${ }^{7-10}$ and 16 about 18 F-FDG PET/CT ${ }^{11-25}$

\section{Qualitative analysis}

Characteristics of the studies are detailed in Tables 1 and 2. The IE group included 16 [18F] FDG PET/CT (overall 988 patients) and four SPECT/CT studies (overall 166 patients). Among the PET/CT studies, seven analyzed only prosthetic valve endocarditis (PVE), $, 13,15,16,19-21$ two only native valve endocarditis (NVE), ${ }^{11,23}$ and the remaining seven analyzed a mixed population or the type of endocarditis was not reported. $12,14,17,18,22,24,25$ Among SPECT studies, two included only PVE, ${ }^{8,9}$ and the remaining two papers included both NVE and PVE.,10 In only one paper, ${ }^{9}$ both SPECT and PET/CT techniques were used to study IE.

The pooled sensitivity of 18F-FDG PET/CT was $68 \%$ (95\% CI 55-87), with a high heterogeneity (I2 $=94 \%$, $\mathrm{p}<0.001$ ), whereas pooled sensitivity of WBC SPECT was $80 \%$ (95\% CI 67-94) with a lower heterogeneity (I2 $=75 \%, \mathrm{p}=0.017$ ). The pooled specificity of 18F-FDGPET/ CT was $86.8 \%$ (95\% CI 82-95) with a high heterogeneity (I2 $=86 \%, p<0.001)$, whereas WBC SPECT showed a pooled specificity of $98 \%$ (95\% CI 94-100) with no heterogeneity ( $\mathrm{I} 2=0 \%, \mathrm{p}=0.625)$. In a sub-analysis, pooled sensitivity of 18F-FDG PET/CT and WBC SPECT for NVE was $71 \%$ (95\% CI 49-93) with a high heterogeneity (I2 $=95 \%, \mathrm{p}<0.001)$, while pooled sensitivity for PVE was $81 \%$ (95\% CI 78-93) with a significant heterogeneity (I2 $=67 \%, p<0.001)$. Pooled specificity of 18F-FDG PET/ CT and WBC SPECT for NVE was 96\% (95\% CI 93-100) with a low heterogeneity (I2 $=52 \%, p=0.016$ ), while pooled specificity for PVE was $92 \%$ (95\% CI 86-96) with a significant heterogeneity ( $(2=79 \%, p<0.001)$.

Of 17 manuscripts considering the diagnostic performance of 18F-FDG PET/CT, 11 showed specific preparation before PET/CT scan $[9,13,15-18,21-25]$ and five did not. ${ }^{11,12,14,19,20}$ In six studies, ${ }^{9,13,21-24}$ participants underwent dietary preparation to promote myocardial suppression (high-fat, low-carbohydrate diet), without heparin injection; in two studied only heparin injection was suggested; ${ }^{16,18}$ in the remaining three works, ${ }^{15,17,25}$ both myocardial suppression and heparin injection were done. Despite this, there was strong heterogeneity in 


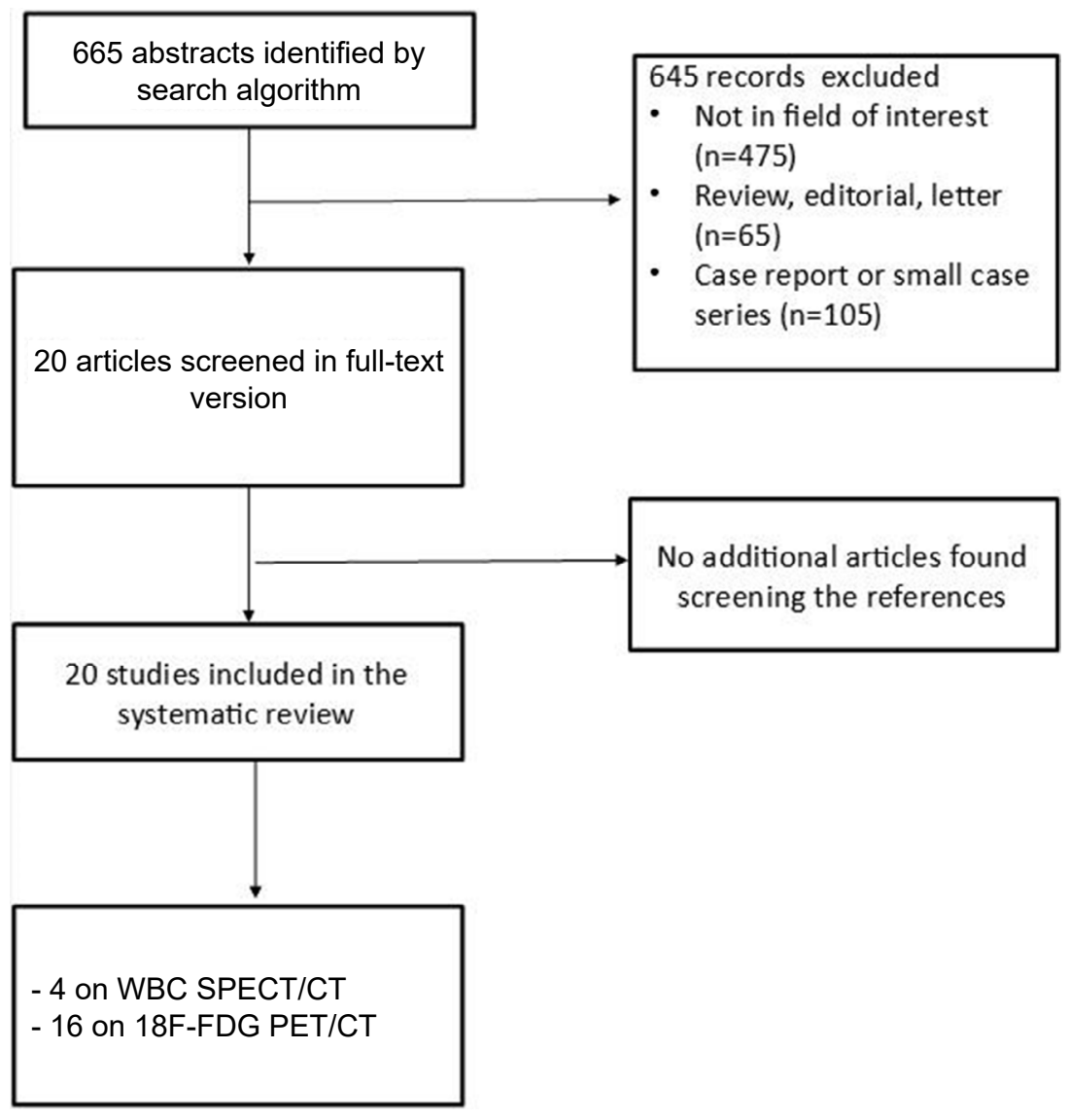

Figure 1 - Flow-chart of the search strategy.

Table 1 - Characteristics of the studies on single photon emission computed tomography using radiolabelled white blood cell and infectious endocarditis

\begin{tabular}{|c|c|c|c|c|c|c|c|c|c|}
\hline Author & Year & Design study & N pts & $\begin{array}{l}\text { Clinical } \\
\text { setting }\end{array}$ & Sensitivity & Specificity & Accuracy & $\begin{array}{l}\text { Diagnostic } \\
\text { criteria }\end{array}$ & Reference standard \\
\hline $\begin{array}{l}\text { Erba et } \\
\text { al. }\end{array}$ & 2012 & Retrospective & 51 & $\begin{array}{l}16 \text { NVE, } \\
35 \text { PVE }\end{array}$ & $90 \%$ & $\mathrm{nr}$ & $90 \%$ & Visual analysis & $\begin{array}{c}\text { Microbiological analysis } \\
\text { or clinical follow-up }\end{array}$ \\
\hline $\begin{array}{l}\text { Hyafil } \\
\text { et al. }\end{array}$ & 2013 & Retrospective & 42 & 42 PVE & $\mathrm{nr}$ & $100 \%$ & $\mathrm{nr}$ & Visual analysis & $\begin{array}{c}\text { Pre-operative } \\
\text { macroscopic analysis and } \\
\text { bacteriological analysis }+ \\
\text { clinical follow-up }\end{array}$ \\
\hline $\begin{array}{l}\text { Rouzet } \\
\text { et al. }\end{array}$ & 2014 & Retrospective & 39 & 39 PVE & $65 \%$ & $100 \%$ & $86 \%$ & $\begin{array}{c}\text { Visual and } \\
\text { semiquantitative } \\
\text { analysis }\end{array}$ & $\begin{array}{c}\text { Combination of modified } \\
\text { Duke criteria and clinical } \\
\text { follow-up }\end{array}$ \\
\hline $\begin{array}{l}\text { Caobelli } \\
\text { et al. }\end{array}$ & 2017 & Retrospective & 34 & $\begin{array}{l}12 \text { NVE, } \\
22 \text { PVE }\end{array}$ & $86 \%$ & $95 \%$ & $91 \%$ & Visual analysis & $\begin{array}{l}\text { Microbiological analysis } \\
\quad+\text { combination of } \\
\text { modified Duke criteria } \\
\text { and clinical follow-up }\end{array}$ \\
\hline
\end{tabular}


Table 2 - Characteristics of the studies on fluorine-18-fluorodeoxyglucose positron emission tomography/computed tomography (18F-FDG PET/CT) and infectious endocarditis

\begin{tabular}{|c|c|c|c|c|c|c|c|c|c|}
\hline Author & Year & $\begin{array}{l}\text { Design } \\
\text { study }\end{array}$ & N pts & $\begin{array}{l}\text { Clinical } \\
\text { setting }\end{array}$ & Sensitivity & Specificity & Accuracy & Diagnostic criteria & Reference standard \\
\hline $\begin{array}{l}\text { Van Riet } \\
\text { et al. }\end{array}$ & 2010 & Prospective & 25 & $25 \mathrm{NVE}$ & $12 \%$ & $100 \%$ & $18 \%$ & Visual analysis & Clinical follow-up \\
\hline $\begin{array}{l}\text { Ozcan } \\
\text { et al. }\end{array}$ & 2013 & Retrospective & 72 & $\begin{array}{l}12 \text { PVE, } \\
52 \text { NVE }\end{array}$ & $18 \%$ & $\mathrm{nr}$ & $18 \%$ & Visual analysis & Clinical follow-up \\
\hline Saby et al. & 2013 & Prospective & 72 & 72 PVE & $73 \%$ & $80 \%$ & $76 \%$ & $\begin{array}{l}\text { Visual analysis } \\
\text { (AC and NAC) }\end{array}$ & $\begin{array}{l}\text { Modified Duke criteria } \\
\text { and clinical follow-up }\end{array}$ \\
\hline $\begin{array}{l}\text { Kouijzer } \\
\text { et al. }\end{array}$ & 2013 & Prospective & 72 & $\mathrm{nr}$ & $39 \%$ & $93 \%$ & $\mathrm{nr}$ & Visual analysis & Modified Duke criteria \\
\hline $\begin{array}{l}\text { Rouzet } \\
\text { et al. }\end{array}$ & 2014 & Retrospective & 39 & 39 PVE & $93 \%$ & $71 \%$ & $80 \%$ & $\begin{array}{c}\text { Visual (AC and NAC) } \\
\text { and semiquantitative } \\
\text { analysis }\end{array}$ & $\begin{array}{l}\text { Modified Duke criteria } \\
\text { and clinical follow-up }\end{array}$ \\
\hline $\begin{array}{l}\text { Ricciardi } \\
\text { et al. }\end{array}$ & 2014 & Retrospective & 27 & 27 PVE & $55 \%$ & $100 \%$ & $\mathrm{nr}$ & $\begin{array}{l}\text { Visual (AC and NAC) } \\
\text { and semiquantitative } \\
\text { analysis }\end{array}$ & $\begin{array}{c}\text { Modified Duke } \\
\text { criteria and clinical/ } \\
\text { microbiological } \\
\text { follow-up }\end{array}$ \\
\hline Pizzi et al. & 2015 & Prospective & 92 & 92 PVE & $87 \%$ & $92 \%$ & $\mathrm{nr}$ & $\begin{array}{c}\text { Visual (AC and NAC) } \\
\text { and semiquantitative } \\
\text { analysis }\end{array}$ & $\begin{array}{l}\text { Modified Duke criteria } \\
\text { and clinical follow-up }\end{array}$ \\
\hline $\begin{array}{l}\text { Jimenez- } \\
\text { Ballvè et } \\
\text { al. }\end{array}$ & 2016 & Prospective & 41 & $\begin{array}{l}39 \text { PVE, } 2 \\
\text { NVE }\end{array}$ & $88 \%$ & $79 \%$ & $85 \%$ & Visual (AC and NAC) & $\begin{array}{c}\text { Modified Duke } \\
\text { criteria and clinical/ } \\
\text { microbiological } \\
\text { follow-up }\end{array}$ \\
\hline $\begin{array}{l}\text { Granados } \\
\text { et al. }\end{array}$ & 2016 & Prospective & 51 & $\begin{array}{l}29 \text { PVE, } \\
21 \mathrm{NVE}\end{array}$ & $82 \%$ & $96 \%$ & $\mathrm{nr}$ & $\begin{array}{l}\text { Visual (AC and NAC) } \\
\text { analysis }\end{array}$ & $\begin{array}{c}\text { Clinical, imaging } \\
\text { and microbiological } \\
\text { follow-up }\end{array}$ \\
\hline $\begin{array}{l}\text { Fagman } \\
\text { et al. }\end{array}$ & 2016 & Retrospective & 30 & $30 \mathrm{PVE}$ & $75 \%$ & $86 \%$ & $83 \%$ & $\begin{array}{l}\text { Visual (AC and NAC) } \\
\text { and semiquantitative } \\
\text { analysis }\end{array}$ & $\begin{array}{c}\text { Modified Duke } \\
\text { criteria and clinical/ } \\
\text { microbiological } \\
\text { follow-up }\end{array}$ \\
\hline $\begin{array}{l}\text { Guenther } \\
\text { et al. }\end{array}$ & 2017 & Retrospective & 26 & 26 PVE & $94 \%$ & $29 \%$ & $76 \%$ & $\begin{array}{c}\text { Visual and } \\
\text { semiquantitative analysis }\end{array}$ & $\begin{array}{l}\text { Modified Duke criteria } \\
\text { and clinical follow-up }\end{array}$ \\
\hline $\begin{array}{l}\text { Salomaki } \\
\text { et al. }\end{array}$ & 2017 & Prospective & 23 & $\begin{array}{l}16 \text { PVE, } 7 \\
\text { NVE }\end{array}$ & $100 \%$ & $71 \%$ & $91 \%$ & $\begin{array}{c}\text { Visual (AC and NAC) } \\
\text { and semiquantitative } \\
\text { analysis }\end{array}$ & $\begin{array}{c}\text { Modified Duke } \\
\text { criteria and clinical/ } \\
\text { microbiological } \\
\text { follow-up }\end{array}$ \\
\hline $\begin{array}{l}\text { Kouijzer } \\
\text { et al. }\end{array}$ & 2018 & Retrospective & 88 & $88 \mathrm{NVE}$ & $45 \%$ & $100 \%$ & $87.5 \%$ & $\begin{array}{l}\text { Visual (AC and NAC) } \\
\text { analysis }\end{array}$ & $\begin{array}{c}\text { Modified Duke } \\
\text { criteria and clinical/ } \\
\text { microbiological } \\
\text { follow-up }\end{array}$ \\
\hline $\begin{array}{l}\text { de } \\
\text { Camargo } \\
\text { et al. }\end{array}$ & 2019 & Prospective & 303 & $\begin{array}{l}188 \text { PVE, } \\
115 \text { NVE }\end{array}$ & $\begin{array}{l}93 \% \text { PVE } \\
70 \% \text { NVE }\end{array}$ & $\begin{array}{l}90 \% \text { PVE } \\
93 \% \mathrm{NVE}\end{array}$ & $\begin{array}{c}91 \% \text { PVE } \\
69 \% \\
\text { NVE }\end{array}$ & $\begin{array}{c}\text { Visual (AC and NAC) } \\
\text { and semiquantitative } \\
\text { analysis }\end{array}$ & Modified Duke criteria \\
\hline $\begin{array}{l}\text { El-Dalati } \\
\text { et al. }\end{array}$ & 2019 & Retrospective & 14 & $\begin{array}{l}8 \text { PVE, } 6 \\
\text { NVE }\end{array}$ & $\mathrm{nr}$ & $100 \%$ & $\mathrm{nr}$ & $\begin{array}{c}\text { Visual (AC and NAC) } \\
\text { and semiquantitative } \\
\text { analysis }\end{array}$ & Histological diagnosis \\
\hline
\end{tabular}




\begin{tabular}{|c|c|c|c|c|}
\hline Author & $\mathbf{N}$ pts & Diet & Heparin & Specific preparation \\
\hline Van Riet et al. & 25 & no & no & 4-hour fasting \\
\hline Ozcan et al. & 72 & no & no & 6-hour fasting (4-hour for diabetic patients) \\
\hline Saby et al. & 72 & yes & no & HFLW (only one meal) diet, 12-hour fasting \\
\hline Kouijzer et al. & 72 & no & no & 6-hour fasting \\
\hline Rouzet et al. & 39 & yes & no & HFLW (only one meal) diet, 12-hour fasting \\
\hline Ricciardi et al. & 27 & yes & yes & HFLW diet, 6-hour fasting \\
\hline Pizzi et al. & 92 & no & yes & 12-hour fasting, $50 \mathrm{IU} / \mathrm{Kg}$ heparin bolus $15 \mathrm{~min}$ before FDG \\
\hline Jimenez-Ballvè et al. & 41 & yes & yes & 48-hours HFLC diet, 12-hour fasting, $50 \mathrm{IU} / \mathrm{Kg}$ heparin bolus $15 \mathrm{~min}$ before FDG \\
\hline Granados et al. & 51 & no & yes & 12-hour fasting, $50 \mathrm{IU} / \mathrm{Kg}$ heparin bolus $15 \mathrm{~min}$ before FDG \\
\hline Fagman et al. & 30 & no & no & 18-hour fasting \\
\hline Kokalova et al. & 13 & no & no & 6-hour fasting \\
\hline Guenther et al. & 26 & yes & no & HFLW diet, 12-hour fasting \\
\hline Salomaki et al. & 23 & yes & no & 24-hour HFLW diet, 10-hour fasting \\
\hline Kouijzer et al. & 88 & yes & no & 24-hour HFLW diet, 6-hour fasting \\
\hline de Camargo et al. & 303 & yes & no & 24-hour HFLW diet, 8-hour fasting \\
\hline El-Dalati et al. & 14 & yes & yes & $\begin{array}{c}\text { 36-hour HFLC diet, } 30 \mathrm{IU} / \mathrm{kg} \text { of heparin administered in three boluses }(10 \mathrm{IU} / \mathrm{kg} \text { ) } \\
\text { at } 10 \mathrm{~min} \text { before FDG and } 5 \text { and } 20 \mathrm{~min} \text { after FDG }\end{array}$ \\
\hline
\end{tabular}

preparation for $\mathrm{PET} / \mathrm{CT}$, with different time of fasting or diet for myocardial suppression (Table 3). Pooled sensitivity of PET/CT was $47 \%$ (95\% CI 18-81) in patients without specific protocol and 78\% (95\% CI 45-99) in patients who performed specific preparation (myocardial suppression diet and/or heparin injection).

Pooled sensitivity of PET/CT was 76\% (95\% CI 64-88) and $72 \%$ (95\% CI 46-99) in patients with and without specific preparation, indicating a high heterogeneity. Also, a pooled specificity of $93 \%$ (95\% CI $70-100)$ was observed in the first group and $91 \%$ (95\% CI 85-94) in the second group.

\section{Discussion}

An accurate diagnosis of IE is critical for clinical decision making and represents a challenge for clinicians; in the latest update of the European Society of Cardiology Guideline ${ }^{26}$ nuclear medicine imaging was integrated in the diagnostic flow-chart of IE. Although blood cultures and echocardiography continue to play a crucial role in the diagnosis and the subsequent clinical management of IE, they have limitations, with a significant number of doubtful reports. Also, ultrasound may have difficulties to study prosthetic valves and inconclusive results have been reported in up to $30 \%$ of cases. ${ }^{27}$

In this context, WBC SPECT and 18F-FDG PET/ $\mathrm{CT}$ studies have demonstrated a significant impact on the study of both PVE and NVE. In particular, in case of suspected PVE, abnormal 18F-FDG PET/CT and WBC SPECT/CT uptake should be considered as a pathological finding. In this systematic review we included 19 studies, with a total of 1,115 patients. Overall, 18F-FDG PET/CT had good specificity (86\%) and low sensitivity (68\%), with high heterogeneity among papers, while WBC SPECT had high specificity $(98 \%)$ and good sensitivity $(80 \%)$ but a small number of patients evaluated.

Our results are similar to those reported in previous reviews and meta-analysis., ${ }^{4,5}$ 
The 18F-FDG PET/CT has the advantage to be a wholebody study that allows the assessment of extracardiac sites of the disease, including clinically unsuspected distant foci, and more appropriate and timely intervention, including antibiotic therapy. In fact, whole-body 18F-FDG PET/CT leads to treatment modification in up to $35 \%$ of patients with IE. ${ }^{28}$ Several factors, such as antimicrobial therapy, small vegetation size and elevated blood glucose level may impact the accuracy of PET/CT and increase the number of false negative findings. The difficulty to detect small vegetations is directly related to the resolution power of the PET/CT device (about 4-5 $\mathrm{mm}$ ), which is aggravated in case of high FDG uptake in the surrounding myocardium.

Physiological uptake of FDG is a common problem in the evaluation of heart infection; for this reason, preparation protocols before and/or after FDG injection were suggested, like dietary preparation for MS and heparin injection. However, different diets have been proposed in the literature, without consensus (Table 3 ). These MS protocols include patient preparation with the use of a low-carbohydrate and high-fat diet plus fasting for at least 6 hours, and use of heparin prior to imaging. Prolonged fasting and low-carbohydrate, high-fat diets lead to decreased insulin and blood glucose levels, and increased free fatty acid levels, reducing physiological FDG uptake. Heparin induces lipolysis and leads to an increase in free fatty acid levels.

Another possible limitation affecting FDG evaluation of IE is the time between valve surgical procedure and PET/CT scan; PET/CT studies performed shortly after cardiac procedures can also be affected by the presence of inflammation foci near to the prostheses.

Although 18F-FDG PET/CT is generally considered a method with higher accuracy than SPECT due to higher spatial resolution and detection efficiency, this was not observed in our results. In fact, in our analysis, both sensitivity and specificity of WBC SPECT were better than PET/CT. 18F-FDG PET/CT has several clear advantages over SPECT imaging such as the lack of blood handling, a shorter study time and high target-to-background ratio; however, a high specificity of 18F-FDG PET/CT requires specific protocols to increase diagnostic accuracy. ${ }^{29,30}$

\section{Limitation of the studies}

Several limitations affect the quality of our review on the role of SPECT and PET in IE such as the lack of multicenter studies, the low number of patients evaluated (also due to the rarity of this disease), and the heterogeneity of included papers. This heterogeneity arises from the diversity of patients' characteristics, methodological aspects, reference standards and global quality of the studies.

\section{Conclusion}

Our findings support the utility of both WBC SPECT and 18F-FDGPET/CT as diagnostic tools in the study of IE, particularly in patients with prosthetic valve. Specific protocols including diet and/or heparin injection may improve the diagnostic performance of PET/CT.

\section{Author contributions}

Conception and design of the research: Bertagna F, Giubbini R. Acquisition of data: Albano D. Analysis and interpretation of the data: Albano D, Bertagna F, Giubbini R. Statistical analysis: Albano D. Writing of the manuscript: Albano D. Critical revision of the manuscript for intellectual content: Albano D, Bertagna F, Giubbini R.

\section{Potential Conflict of Interest}

No potential conflict of interest relevant to this article was reported.

\section{Sources of Funding}

There were no external funding sources for this study.

\section{Study Association}

This study is not associated with any thesis or dissertation work.

\section{Ethics approval and consent to participate}

This article does not contain any studies with human participants or animals performed by any of the authors.

\section{References}

1. Thuny F, Grisoli D, Cautela J, Riberi A, Raoult D, Habib G. Infective endocarditis: prevention, diagnosis, and management. Can J Cardiol. 2014;30(9):1046-57.

2. Thuny F, Grisoli D, Collart F, Habib G, Raoult D. Management of infective endocarditis: challenges and perspectives. Lancet. 2012;379(9819):965-75. 
3. Li JS, Sexton DJ, Mick N, Nettles R, Fowler VG Jr, Ryan T, et al. Proposed modifications to the Duke criteria for the diagnosis of infective endocarditis. Clin Infect Dis. 2000;30(4):633-8.

4. Cantoni V, Sollini M, Green R, Berchiolli R, Lazzeri E, Mannarino T, et al Comprehensive meta-analysis on [18F] FDG PET/CT and radiolabelled leukocyte SPECT-SPECT/CT imaging in infectious endocarditis and cardiovascular implantable electronic device infections. Clin Transl Imaging. 2018;6(1):3-18.

5. Juneau D, Golfam M, Hazra S, Erthal F, Zuckier LS, Bernick J, et al. Molecular imaging for the diagnosis of infective endocarditis: a systematic literature review and meta-analysis. Int J Cardiol. 2018 Feb 15;253:183-8.

6. Liberati A, Altman DG, Tetzlaff J, Mulrow C, Gøtzsche PC, Ioannidis JP, et al. The PRISMA statement for reporting systematic reviews and metaanalyses of studies that evaluate health care interventions: explanation and elaboration. J Clin Epidemiol. 2009;62(10):e1-34.

7. Erba PA, Conti U, Lazzeri E, Sollini M, Doria R, De Tommasi SM, et al. Added value of 99mTc-HMPAOlabeled leukocyte SPECT/CT in the characterization and management of patients with infectious endocarditis. J Nucl Med. 2012;53(8):1235-43.

8. Hyafil F, Rouzet F, Lepage L, Benali K, Raffoul R, Duval X, et al. Role of radiolabelled leucocyte scintigraphy in patients with a suspicion of prosthetic valve endocarditis and inconclusive echocardiography. Eur Heart J Cardiovasc Imaging. 2013;14(6):586-94.

9. Rouzet F, Chequer R, Benali K, Lepage L, Ghodbane W, Duval X, et al. Respective performance of 18F-FDG PET and radiolabelled leukocyte scintigraphy for the diagnosis of prosthetic valve endocarditis. J Nucl Med. 2014;55(12):1980-5.

10. Caobelli F, Wollenweber T, Bavendiek U, Kühn C, Schütze C, Geworski L, et al. Simultaneous dual-isotope solid-state detector SPECT for improved tracking of white blood cells in suspected endocarditis. Eur Heart J. 2017;38(6):436-43.

11. Van Riet J, Hill EE, Gheysens O, Dymarkowski S, Herregods MC, Herijgers $\mathrm{P}$, et al. (18) F-FDG PET/CT for early detection of embolism and metastatic infection in patients with infective endocarditis. Eur J Nucl Med Mol Imaging. 2010;37(6):1189-97.

12. Özcan C, Asmar A, Gill S, Thomassen A, Diederichsen AC. The value of FDG-PET/CT in the diagnostic work-up of extra cardiac infectious manifestations in infectious endocarditis. Int J Cardiovasc Imaging. 2013;29(7):1629-37.

13. Saby L, Laas O, Habib G, Cammilleri S, Mancini J, Tessonnier L, et al. Positron emission tomography/computed tomography for diagnosis of prosthetic valve endocarditis: increased valvular $18 \mathrm{~F}$-fluorodeoxyglucose uptake as a novel major criterion. J Am Coll Cardiol. 2013;61(23):2374-82.

14. Kouijzer IJ, Vos FJ, Janssen MJ, van Dijk AP, Oyen WJ, Bleeker-Rovers $\mathrm{CP}$. The value of 18FFDG PET/CT in diagnosing infectious endocarditis. Eur J Nucl Med Mol Imaging. 2013;40(7):1102-7.

15. Ricciardi A, Sordillo P, Ceccarelli L, Maffongelli G, Calisti G, Di Pietro $\mathrm{B}$, et al. 18-Fluoro-2-deoxyglucose positron emission tomographycomputed tomography: an additional tool in the diagnosis of prosthetic valve endocarditis. Int J Infect Dis. 2014 Nov;28:219-24.

16. Pizzi MN, Roque A, Fernández-Hidalgo N, Cuéllar-Calabria H, FerreiraGonzález I, Gonzàlez-Alujas MT, et al. Improving the diagnosis of infective endocarditis in prosthetic valves and intracardiac devices with 18 F-fluordeoxyglucose positron emission tomography/computed tomography angiography: initial results at an infective endocarditis referral center. Circulation. 2015;132(12):1113-26.

17. Jiménez-Ballvé A, Pérez-Castejón MJ, Delgado-Bolton RC, SánchezEnrique C, Vilacosta I, Vivas D, et al. Assessment of the diagnostic accuracy of 18F-FDG PET/CT in prosthetic infective endocarditis and cardiac implantable electronic device infection: comparison of different interpretation criteria. Eur J Nucl Med Mol Imaging. 2016;43(13):2401-12.

18. Granados U, Fuster D, Pericas JM, Llopis JL, Ninot S, Quintana E, et al. Diagnostic accuracy of 18F-FDG PET/CT in infective endocarditis and implantable cardiac electronic device infection: a cross-sectional study. J Nucl Med. 2016;57(11):1726-32.

19. Fagman E, van Essen M, Fredén Lindqvist J, Snygg-Martin U, BechHanssen O, Svensson G. 18F-FDG PET/CT in the diagnosis of prosthetic valve endocarditis. Int J Cardiovasc Imaging. 2016;32(4):679-86.

20. Kokalova A, Dell'Aquila AM, Avramovic N, Martens S, Wenning C, Sindermann JR. Supporting imaging modalities for improving diagnosis of prosthesis endocarditis: preliminary results of a single-center experience with 18F-FDG-PET/CT. Minerva Med. 2017;108(4):299-304.

21. Guenther SPW, Cyran CC, Rominger A, Saam T, Kazmierzcak PM, Bagaev E, et al. The relevance of $18 \mathrm{~F}$-fluorodeoxyglucose positron emission tomography/computed tomography imaging in diagnosing prosthetic graft infections post cardiac and proximal thoracic aortic surgery. Interact Cardiovasc Thorac Surg. 2015;21(4):450-8.

22. Salomäki SP, Saraste A, Kemppainen J, Bax JJ, Knuuti J, Nuutila P, et al. 18F-FDG positron emission tomography/computed tomography in infective endocarditis. J Nucl Cardiol. 2017;24(1):195-206.

23. Kouijzer IJE, Berrevoets MAH, Aarntzen EHJG, de Vries J, van Dijk APJ, Oyen WJG, et al. 18F-fluorodeoxyglucose positron-emission tomography combined with computed tomography as a diagnostic tool in native valve endocarditis. Nucl Med Comm. 2018;39(8):747-52.

24. de Camargo RA, Bitencourt MS, Meneghetti JC, Soares J, Gonçalves LFT, Buchpiguel CA, et al. The role of 18F-FDG-PET/CT in the diagnosis of left-sided endocarditis: native vs. prosthetic valves endocarditis. Clin Infect Dis. 2019 Apr 5;pii:ciz267.

25. El-Dalati S, Murthy VL, Owczarczyk AB, Fagan C, Riddell J 4th, Cinti S, et al. Correlating cardiac F-18 FDG PET/CT results with intra-operative findings in infectious endocarditis. J Nucl Cardiol. 2019 Sep 4.

26. Habib G, Lancellotti P, Antunes MJ, Bongiorni MG, Casalta JP, Zotti F, et al. 2015 ESC Guidelines for the management of infective endocarditis: The Task Force for the Management of Infective Endocarditis of the European Society of Cardiology (ESC). Eur Heart J. 2015;36(44):3075-3128.

27. Saby L, Laas O, Habib G, Cammilleri S, Mancini J, Tessonnier L, et al. Positron emission tomography/computed tomography for diagnosis of prosthetic valve endocarditis: increased valvular 18F-fluorodeoxyglucose uptake as a novel major criterion. J Am Coll Cardiol. 2013;61(23):2374-82.

28. Orvin K, Goldberg E, Bernstine H, Groshar D, Sagie A, Kornowski $\mathrm{R}$, et al. The role of FDG-PET/CT imaging in early detection of extracardiac complications of infective endocarditis. Clin Microbiol Infect. 2015;21(1):69-76.

29. Bertagna F, Giubbini R, Treglia G. Positron emission tomography/computed tomography for diagnosis of prosthetic valve endocarditis: suggestions to increase diagnostic accuracy. J Am Coll Cardiol. 2014;63(4):378-9.

30. Treglia G, Bertagna F. Factors influencing the sensitivity of 18F-FDG PET/CT in the detection of infective endocarditis. Eur J Nucl Med Mol Imaging. 2013;40(7):1112-3. 